\title{
Regulation of airway smooth muscle RhoA/ ROCK activities by cholinergic and bronchodilator stimuli
}

\author{
C. Liu, J. Zuo and L.J. Janssen
}

ABSTRACT: The current study set out to compare the temporal relationships of Rho activity, Rho kinase (ROCK) activity and tone following cholinergic stimulation in the presence and absence of three different bronchodilators.

Bovine trachea challenged with a half-maximally effective concentration of carbachol (CCh) was flash-frozen at different times, then assayed for Rho (rhotekin pull-down assay) and ROCK (Western blot; radiometric assay) activities.

Rho was activated within $30 \mathrm{~s}$, followed by ROCK (peak at $2 \mathrm{~min}$ ); both returned to baseline by $20 \mathrm{~min}$, although tone continued to rise over that period. Increasing the concentration of $\mathrm{CCh}$ greatly increased the magnitudes and rates of stimulation of Rho, ROCK and tone. These CChinduced changes were next compared in tissues pre-treated with isoproterenol, salmeterol or the nitric oxide donor S-nitroso- $\mathrm{N}$-acetylpenicillamine (SNAP). Neither the time course nor the magnitude of Rho-activation were reduced by the $\beta$-agonists; SNAP slowed Rho activation but it did not alter the peak magnitude. These observations were mirrored in ROCK activation and contraction. When tissues were pre-constricted with $\mathrm{CCh}$ and then challenged with the bronchodilators, however, all three agonists reversed cholinergically stimulated Rho, ROCK and myosin light chain kinase activities as well as tone.

In conclusion, bronchodilators can suppress RhoA and Rho kinase activities, although their major effect appears to be on myosin light chain kinase activity.

KEYWORDS: Adrenergic, airway smooth muscle, cholinergic, nitric oxide, RhoA, Rho kinase

$\mathbf{A}$ great deal has been learned about the diverse signalling events underlying the cholinergic excitation of airway smooth muscle. For instance, $\mathrm{M}_{2}$ receptors are coupled negatively to adenylate cyclase, leading to its inhibition [1-3]. Stimulation of muscarinic $\mathrm{M}_{3}$ receptors triggers the phosphoinositide signalling cascade via the heterotrimeric G-protein $\mathrm{G}_{\mathrm{q}, 11}$, resulting in activation of protein kinase $C$ and release of internally sequestered $\mathrm{Ca}^{2+}$ (via production of diacylglycerol and inositol trisphosphate, respectively) [3-5]. $\mathrm{Ca}^{2+}$ release stimulates myosin light chain kinase (MLCK) activity directly $[6,7]$, but may also open plasmalemmal $\mathrm{Cl}^{-}$channels $[8,9]$ leading to membrane depolarisation and voltage-dependent $\mathrm{Ca}^{2+}$ influx. The $M_{3}$ receptors are also coupled to $G_{12,13}$, which activates the monomeric G-protein Rho and its downstream effector Rho-kinase (ROCK) [10]. One of the targets of ROCK is myosin light

For editorial comments see page 680 . chain phosphatase (MLCP), whose activity is suppressed.

There has been a great deal of interest recently in the involvement of the Rho/ROCK signalling pathway in excitation-contraction coupling [1117] and airway hyperresponsiveness [18-22]. However, the data available are limited in many ways. First, most published studies have not measured Rho/ROCK activities directly, but instead have inferred changes in ROCK activity on the basis of the pharmacological effect of the ROCK inhibitor Y27632 on contractile activity. Secondly, generally only a single, supramaximal concentration of excitatory agonist has been used and/or only a single time-point examined. There is a great deal of evidence to suggest that the contribution of various signalling pathways to excitation-contraction coupling varies depending upon the degree and/or duration of excitatory challenge; also, supramaximally effective concentrations are generally not physiologically relevant. Thirdly, the vast majority of the work has been done in vascular smooth muscle

\section{AFFILIATIONS}

Firestone Institute for Respiratory Health, St. Joseph's Hospital and the Dept of Medicine, McMaster University, Hamilton, Ontario, Canada.

CORRESPONDENCE

L.J. Janssen

L-314

St. Joseph's Hospital

50 Charlton Avenue East

Hamilton

Ontario L8N 4A6

Canada

Fax: 19055406510

E-mail: janssenl@mcmaster.ca

Received:

February 192006

Accepted after revision:

May 302006

SUPPORT STATEMENT

This study was supported by an Investigator Career Award from the Canadian Institutes of Health

Research, as well as operating support from the Canadian Institutes of Health Research and the Ontario Thoracic Society of Canada. Salmeterol was kindly provided by GlaxoSmithKline (Mississauga, ON, Canada). 
preparations [23-25], which can employ the same cellular machinery in very different ways (witness the contrary dependence upon electromechanical coupling in vascular and airway smooth muscles, despite both possessing exactly the same voltage-dependent $\mathrm{Ca}^{2+}$ channels). Finally, the regulation of the Rho/ROCK signalling pathway by inhibitory stimuli has remained unexplored.

Understanding of the signalling events underlying inhibitory regulation of airway smooth muscle (ASM), mediated in large part by adrenergic agonists and nitric oxide (NO), is also well developed, but has lagged somewhat behind that pertaining to ASM excitation. Generally speaking, bronchodilators trigger signalling events opposite to those summarised above, including stimulation of the enzymatic activities of adenylate cyclase/protein kinase (PK)A ( $\beta$-agonists) or of guanylate cyclase/PKG (NO), $\mathrm{Ca}^{2+}$ uptake and $\mathrm{Ca}^{2+}$ extrusion, membrane hyperpolarisation, inhibition of MLCK and stimulation of MLCP [7, 10, 26-29]. Interestingly, some of these effects depend upon whether cholinergic stimulation precedes $\beta$-adrenoceptor stimulation, or vice versa $[7,26,27]$. However, a major gap in this picture is the interaction between excitatory and inhibitory inputs at the level of the Rho/ROCK signalling pathway.

The current authors examined the interactions between excitatory (cholinergic) and inhibitory ( $\beta$-adrenergic and NO) agonists with respect to the Rho/ROCK signalling pathway in bovine tracheal smooth muscle (TSM). The objectives were to examine the kinetics of activation of RhoA, ROCK and the contractile apparatus following varying degrees of cholinergic stimulation, and the effects of bronchodilator stimuli on these cholinergic changes. Comparisons were made between the classical $\beta$-agonist isoproterenol (ISO; nonselective), the more recently introduced long-acting $\beta$-agonist salmeterol (SAL; $\beta_{2^{-}}$ selective), and the NO donor $S$-nitroso- $N$-acetylpenicillamine (SNAP). Comparisons were also made between prevention and reversal of cholinergic responses by these agonists.

\section{METHODS}

\section{Preparation of isolated tissues}

Tracheae were obtained from cows (200-500 kg) slaughtered at a local abattoir, and immediately put in ice-cold physiological solution for transport to the laboratory. TSM was isolated by removing connective tissue, vasculature and epithelium, then cut into strips parallel to the muscle fibres ( $\sim 1 \mathrm{~mm}$ wide).

\section{Muscle bath technique}

Tracheal strips were tied with silk suture (Ethicon 4-0; Ethicon, Cornelia, GA, USA) to a Grass FT.03 force transducer (GrassTelefactor, West Warwick, RI, USA) at one end, and to a plexiglass rod which served as an anchor at the other end. These were bathed in Krebs-Ringer's buffer (see below for composition) containing indomethacin $\left(10^{-5} \mathrm{M}\right)$ and $\mathrm{N}-\omega$-nitroL-arginine (L-NNA; $10^{-4} \mathrm{M}$ ), bubbled with $95 \% \mathrm{O}_{2}: 5 \% \mathrm{CO}_{2}$, and maintained at $37^{\circ} \mathrm{C}$; tissues were passively stretched to impose a pre-load tension of $\approx 1 \mathrm{~g}$. Isometric changes in tension were amplified, digitised (2 samples $\cdot \mathrm{s}^{-1}$ ) and recorded (DigiMed System Integrator; MicroMed, Louisville, KY, USA) for plotting on a computer. Tissues were equilibrated for $1 \mathrm{~h}$ before commencing the experiments, during which time they were challenged with $65 \mathrm{mM} \mathrm{KCl}$ three times to assess the functional state of each tissue.

\section{Assay for RhoA activity}

Tissues which had been flash-frozen in liquid nitrogen were homogenised in ice-cold buffer $(50 \mathrm{mM}$ Tris-HCl, $\mathrm{pH} 7.5$, $0.1 \mathrm{mM}$ EDTA, $0.1 \mathrm{mM}$ EGTA, $750 \mathrm{mM} \mathrm{NaCl}$, 5\% Igepal CA$630,50 \mathrm{mM} \mathrm{MgCl}_{2}, 10 \%$ glycerol, $10 \mu \mathrm{g} \cdot \mathrm{mL}^{-1}$ aprotinin, $10 \mu \mathrm{g} \cdot \mathrm{mL}^{-1}$ leupeptin, $1 \mathrm{mM}$ phenylmethylsulphonyl fluoride, $1 \mathrm{mM}$ 4-(2-aminoethyl)-benzenesulfonyl fluoride, $2 \mathrm{mM}$ sodium orthovanadate). Their total protein content was determined (Bradford method) and adjusted (by addition of media) in order to achieve uniformity. Tissue homogenates were incubated $\left(60 \mathrm{~min}\right.$ at $\left.4^{\circ} \mathrm{C}\right)$ with rhotekin-coated cellulose beads (rhotekin specifically binds activated RhoA and not inactive RhoA). The sample was then centrifuged $(14,000 \times g$ for $10 \mathrm{~s}$ at $4{ }^{\circ} \mathrm{C}$ ) to "pull down" the beads and the supernatant (unbound material) was discarded, after which Rho was dissociated from the beads by incubating with Laemmli sample buffer (62.5 mM Tris-HCl, pH 6.8, 2\% sodium dodecyl sulphate (SDS), 10\% glycerol, $50 \mathrm{mM}$ dithiothreitol (DTT), $0.1 \%$ $\beta$-mercaptoethanol, $0.01 \%$ bromophenol blue). Samples were boiled for $5 \mathrm{~min}$, subjected to SDS polyacrylamide gel electrophoresis, then transferred to nitrocellulose membrane (blocked with 3\% bovine serum albumin/Tris-buffered salineTween). RhoA was visualised using a rabbit anti-Rho polyclonal antibody preparation (Upstate Biotechnology Inc., Waltham, MA, USA) followed by secondary horseradish peroxidase-conjugated goat anti-rabbit immunoglobulin G (1:15,000 dilution; Sigma-Aldrich, St Louis, MO, USA). Blots were detected with enhanced chemiluminescence (Amersham, Little Chalfont, UK).

\section{ROCK assay (Western blot)}

Tissues were homogenised and protein content adjusted as outlined previously. Tissue homogenates were incubated $\left(10 \mathrm{~min}\right.$ at $30^{\circ} \mathrm{C}$ ) with $0.5 \mathrm{ng} \mathrm{MYPT}$ (the myosin-targeting subunit of MLCP), after which the reaction was terminated by addition of Laemmli sample buffer. Samples were then subjected to Western blot analysis, as outlined above. Phospho-MYPT was visualised using a rabbit anti-phosphoMYPT1 polyclonal antibody preparation (Upstate Biotechnology Inc.). While it is true that other kinases can also potentially phosphorylate MYPT [30], the current authors have shown previously that the changes in MYPT phosphorylation seen with airway smooth muscle homogenates were sensitive to $\mathrm{Y} 27632$.

\section{ROCK assay ( ${ }^{32} \mathbf{P}$ incorporation)}

Tissue homogenates were centrifuged $(10,000 \times g$ for $10 \mathrm{~min}$ at $4{ }^{\circ} \mathrm{C}$ ). The pellet was resuspended and an aliquot used to quantify the total protein content (Bradford method). The remainder was resuspended $\left(1 \mathrm{mg} \cdot \mathrm{mL}^{-1}\right)$ in kinase assay buffer (20 mM 3-[N-morpholino]propane sulphonic acid, $25 \mathrm{mM} \quad \beta$-glycerophosphate, $15 \mathrm{mM} \mathrm{MgCl}_{2}, 1 \mathrm{mM}$ EGTA, $0.1 \mathrm{mM} \mathrm{NaF}, 1 \mathrm{mM} \mathrm{Na} \mathrm{VO}_{4}, 1 \mathrm{mM}$ DTT, pH 7.2) containing $50 \mu \mathrm{M}$ MYPT as a substrate. The kinase reaction was started by adding $100 \mu \mathrm{M}$ ATP (containing $10 \mu \mathrm{Ci} \cdot \mathrm{mL}^{-1} \gamma^{32} \mathrm{P}$-ATP) and incubated for $10 \mathrm{~min}$ at $30^{\circ} \mathrm{C}$ with agitation. Aliquots of reaction mixture were spotted on P81 paper and washed five times with ice-cold $0.75 \% \mathrm{H}_{3} \mathrm{PO}_{4}$ and then with acetone. Paper squares were dried and radioactivity counted (Cerenkov method). 


\section{MLCK assay}

Flash-frozen bovine TSM tissues were homogenised in ice-cold buffer (50 mM Tris- $\mathrm{HCl}, 0.1 \mathrm{mM}$ EDTA, $0.1 \mathrm{mM}$ EGTA, $0.1 \%$ $\beta$-mercaptoethanol, $25 \mu \mathrm{g} \cdot \mathrm{mL}^{-1}$ aprotinin, $25 \mu \mathrm{g} \cdot \mathrm{mL}^{-1}$ leupeptin, $1 \mathrm{mM}$ 4-(2-aminoethyl)-benzenesulphonyl fluoride, $\mathrm{pH} 7.5$ ), then centrifuged at $13,000 \times g$ for $10 \mathrm{~min}$ at $4^{\circ} \mathrm{C}$. Supernatants were collected and their protein concentrations determined by the Bradford method. Tissue homogenates $(20 \mu \mathrm{g})$ were warmed for $5 \mathrm{~min}$ to $25^{\circ} \mathrm{C}$ in reaction buffer (30 mM Tris- $\mathrm{HCl}, 50 \mathrm{mM} \mathrm{KCl}, 0.1 \mathrm{mM}$ EDTA, $0.1 \% \quad \beta$ mercaptoethanol; $\mathrm{pH} 7.5)$, after which the phosphorylation reaction was initiated by adding myosin $(10 \mu \mathrm{g}$; extracted from porcine stomach using protocols published elsewhere [31]) and ${ }^{32}$ P-ATP (1 mM; $0.5 \mathrm{mCi}$ ), and allowed to proceed for $20 \mathrm{~min}$ at $25^{\circ} \mathrm{C}$; Y27632 was added to prevent ROCK-mediated phosphorylation of myosin. The reaction was terminated by addition of trichloroacetic acid and bovine serum albumin $\left(1 \mathrm{mg} \cdot \mathrm{mL}^{-1}\right)$, left on ice for $10 \mathrm{~min}$, then centrifuged for $10 \mathrm{~min}$ at $13,000 \times g$. Aliquots of supernatant were added to scintillation fluid and counted.

\section{Solutions and chemicals}

Tissues were studied using Krebs-Ringer's buffer containing (in $\mathrm{mM}$ ) $\mathrm{NaCl} 116, \mathrm{KCl} 4.2, \mathrm{CaCl}_{2} 2.5, \mathrm{NaH}_{2} \mathrm{PO}_{4} 1.6, \mathrm{MgSO}_{4} 1.2$, $\mathrm{NaHCO}_{3} 22$, D-glucose 11, bubbled to maintain $\mathrm{pH}$ 7.4. LNNA $\left(10^{-4} \mathrm{M}\right)$ and indomethacin $(10 \mu \mathrm{M})$ were also added to prevent generation of $\mathrm{NO}$ and of cyclo-oxygenase metabolites of arachidonic acid, respectively.

All chemicals were obtained from Sigma-Aldrich and prepared as $10 \mathrm{mM}$ stock solutions, either aqueous (carbachol (CCh), ISO, SNAP) or in absolute ethanol (salmeterol, (+)-(R)-trans-4(1-aminoethyl)- $\mathrm{N}$-(pyridyl) cyclohexanecarboxamide dihydrochloride (Y27632)) or DMSO ((+)-(R)-trans-4-(1-aminoethyl) -N-(pyridyl) cyclohexanecarboxamide dihydrochloride 11-2((2(diethylamino)methyl1)-1-piperidinyl) acetyl-5,11-dihydro-6Hpyrido-(2,3-b)-benzodiazepine-6-one (AFDX-116)). Aliquots were then added to the muscle baths. The final bath concentration of DMSO and ethanol did not exceed $0.1 \%$, which the current authors have found elsewhere to have little or no effect on mechanical activity.

\section{Data analysis}

Cholinergic contractions were expressed as a percentage of the response to $60 \mathrm{mM} \mathrm{KCl}$ added during the equilibration period (immediately before onset of the experiment), whereas adrenergic relaxations were expressed as reversals of preexisting tone (evoked by $\mathrm{CCh}$ or $\mathrm{KCl}$ ). Enzymatic activities were expressed as \% above the activity observed in tissues flash-frozen immediately before addition of CCh (for cholinergic activation study) or those not receiving any inhibitory agonist (adrenergic inhibition study). Data are reported as mean $\pm \mathrm{SEM} ; \mathrm{n}$ refers to the number of animals. Statistical comparisons were made using ANOVA with StudentNewman-Keuls post hoc test; $\mathrm{p}<0.05$ was considered statistically significant.

\section{RESULTS}

\section{Cholinergic and adrenergic concentration-response relationships in bovine TSM}

The current authors first sought to ascertain a concentration of CCh which was half-maximally effective in producing

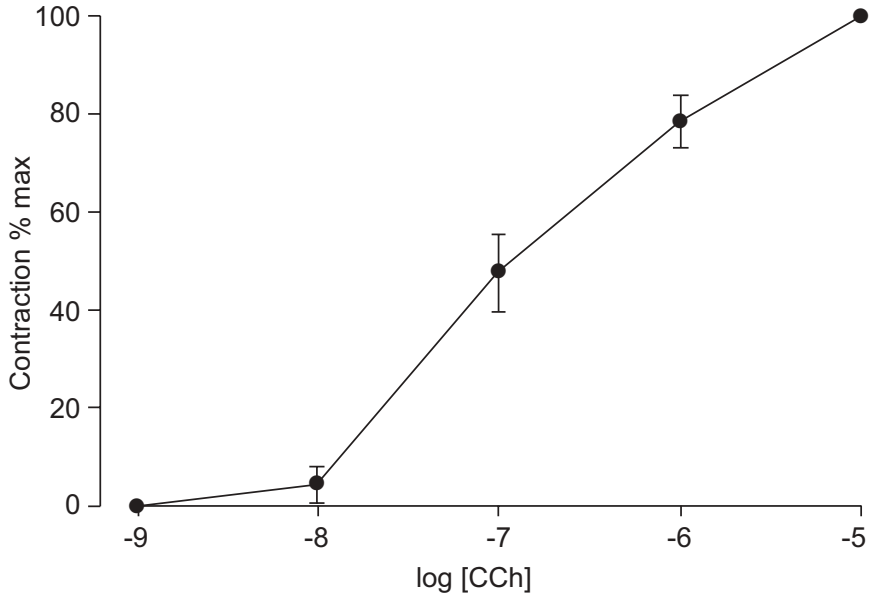

FIGURE 1. Cholinergic and adrenergic concentration-response relationships. Mean concentration-response relationships for carbachol (CCh)-evoked contractions in bovine trachealis. Data are presented as mean \pm SEM. $n=5$.

contraction, as well as the optimal concentrations of bronchodilators to be used in this study.

The concentration-response relationship for $\mathrm{CCh}$ in bovine tracheal strips was examined by challenging the tissues with increasing concentrations $\left(10^{-10}-10^{-5} \mathrm{M}\right.$, in 10 -fold increments) of $\mathrm{CCh}$ in cumulative fashion. These cumulative challenges resulted in sustained contractions with threshold, half-maximally effective and maximally effective $\mathrm{CCh}$ concentrations of $10^{-9} \mathrm{M}, 1.6 \times 10^{-7} \mathrm{M}$, and $10^{-5} \mathrm{M}$, respectively; these values correspond closely to those published previously [32] (fig. 1).

In another set of tissues, pre-constricted with $10^{-7} \mathrm{M} \mathrm{CCh}$ for $20 \mathrm{~min}$, the concentration-response relationships for three different bronchodilators were compared. ISO $\left(10^{-6} \mathrm{M}\right)$ is a short-acting, nonselective $\beta$-agonist with full agonist activity, whereas SAL $\left(10^{-6} \mathrm{M}\right)$ is a long-acting, $\beta_{2}$-selective agonist with only partial agonist activity; both signal through stimulation of adenylate cyclase activity [7]. SNAP $\left(10^{-5} \mathrm{M}\right)$, conversely, is a $\mathrm{NO}$ donor which acts through stimulation of guanylate cyclase. Since the relaxations evoked by SAL were much more delayed and slower in development than those evoked by ISO or SNAP (fig. 2a), the current authors only examined the responses to $10^{-9} \mathrm{M}$ and $10^{-7} \mathrm{MSAL}$, but probed a more complete range of concentrations for ISO and SNAP $\left(10^{-9}-10^{-5} \mathrm{M}\right.$, in 10 -fold increments). The concentration-response relationships obtained in this way are given in figure $2 b$.

Relaxations to submaximal concentrations of ISO and SNAP exhibited a degree of tachyphylaxis. However, reversal of cholinergic tone was complete and sustained at micromolar concentrations $\left(10^{-6} \mathrm{M}\right.$ in the case of ISO and $10^{-5} \mathrm{M}$ in the case of SNAP).

SAL-evoked relaxations, conversely, developed much more slowly and did not exhibit tachyphylaxis over the duration of the experiments. This agent exerted just over $50 \%$ reversal of cholinergic tone when applied at $10^{-7} \mathrm{M}$; higher concentrations were not tested. 


\section{Cholinergic regulation of Rho and ROCK activities and tone}

The temporal relationships between cholinergic stimulation of Rho and ROCK activities, as well as tone, were investigated. Following the equilibration period, bovine tracheal strips were challenged with a half-maximally effective concentration of CCh $\left(2 \times 10^{-7} \mathrm{M}\right)$ and flash-frozen at various times ranging from $30 \mathrm{~s}$ to $20 \mathrm{~min}$, then assayed for Rho and ROCK activities. The results are shown in figure 3a. Rho activity was markedly and significantly increased even $30 \mathrm{~s}$ after addition of the cholinergic agonist, and reached a peak at $2 \mathrm{~min}$, after which it fell toward baseline. As should be expected, changes in ROCK activity paralleled those in Rho activity, albeit with a delay: ROCK activity was not significantly elevated at $30 \mathrm{~s}$, reached a peak at $2 \mathrm{~min}$, then decreased by half at $20 \mathrm{~min}$ following cholinergic stimulation. The increase in mechanical tone lagged even further: this was negligible at $30 \mathrm{~s}$, and less than a third of maximal at 2 min (when Rho and ROCK activities
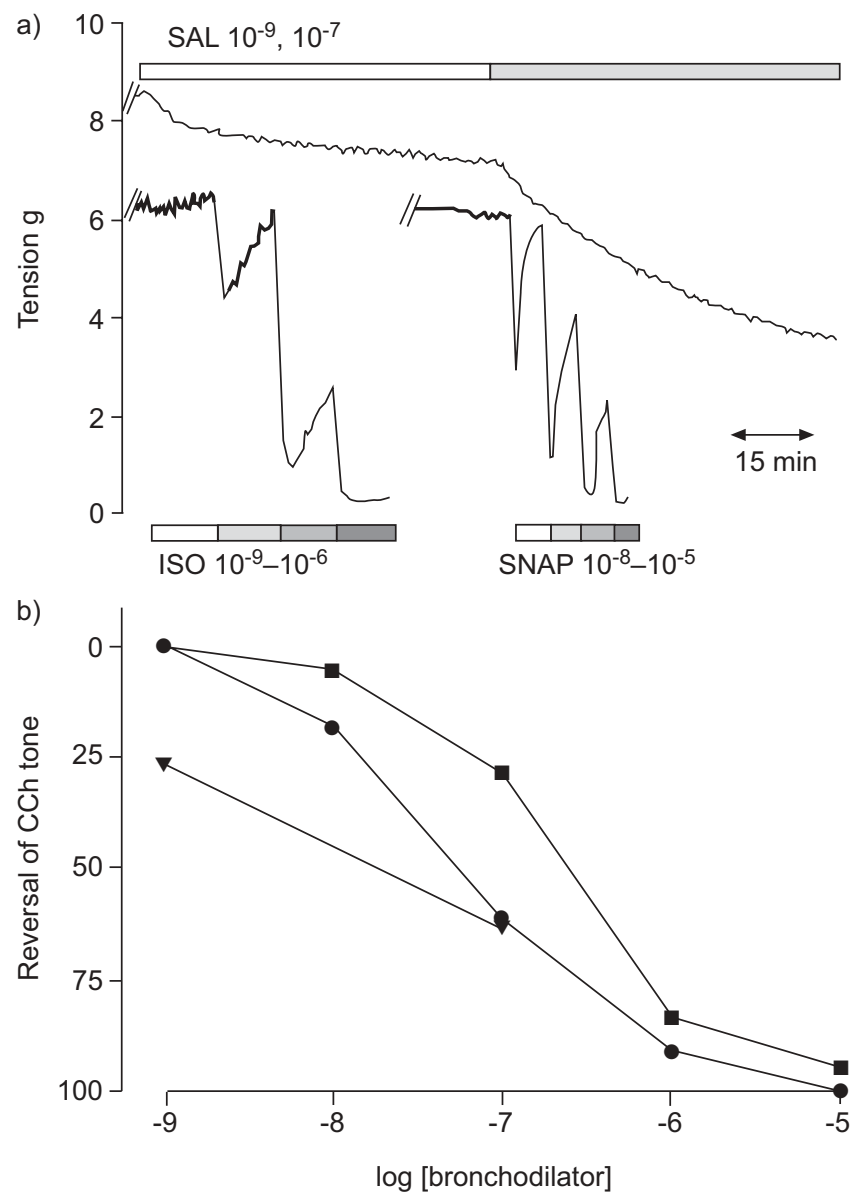

FIGURE 2. Comparison of relaxations evoked by isoproterenol (ISO), salmeterol (SAL) and S-nitroso-N-acetylpenicillamine (SNAP). a) Representative tracings over time of the relaxations evoked by ISO, SAL and SNAP (concentrations as indicated by boxes) in bovine tracheal smooth muscle pre-constricted with $10^{-7} \mathrm{M}$ carbachol (CCh): the cholinergic constrictor response per se has been omitted to emphasise the much slower onset of SAL-mediated relaxation. Tachyphylaxis was often seen when submaximal concentrations of ISO or SNAP were used, but not at higher concentrations, or in the case of SAL. b) Mean concentration-response relationships for ISO $(\bullet), \operatorname{SAL}(\boldsymbol{\nabla})$ and $\operatorname{SNAP}(\boldsymbol{\square})$ obtained using protocol illustrated in a). $n>5$ for all. had peaked), reaching a stable plateau by $20 \mathrm{~min}$. In contrast to the decay toward baseline in the enzymatic activities, peak contraction was followed by very little reversal of tone.

Increasing the concentration of $\mathrm{CCh}$ from $2 \times 10^{-7} \mathrm{M}$ to $10^{-6} \mathrm{M}$ increased the magnitudes and rates of increase of Rho and ROCK activities, with parallel changes in tone (fig. $3 b$ ). In particular, Rho activity was more than doubled above baseline by $2 \mathrm{~min}$, and remained stimulated to this level by $20 \mathrm{~min}$, whereas ROCK activity was increased $\sim 60 \%$ above baseline by $2 \mathrm{~min}$ and then declined slightly over the next 15-20 min. As described previously, tone was negligibly affected at $30 \mathrm{~s}$ (despite substantial enhancement of Rho and ROCK activities), but was nearly maximal by $10 \mathrm{~min}$, with marginal decay by $20 \mathrm{~min}$.

\section{Regulation of Rho and ROCK by $\beta$-agonists versus SNAP} Cholinergic stimulation of Rho and ROCK activities and tone were compared in tissues pre-treated with ISO $\left(10^{-6} \mathrm{M}\right)$, SAL $\left(10^{-7} \mathrm{M}\right)$ or SNAP $\left(10^{-5} \mathrm{M}\right)$; given the longer time-course for SAL-mediated changes (fig. 2a), tissues were pre-treated for $30 \mathrm{~min}$ in the case of ISO or SNAP but $60 \mathrm{~min}$ in the case of SAL. Following this pre-treatment, tissues were challenged with $2 \times 10^{-7} \mathrm{M} \mathrm{CCh}$, then flash-frozen at different time-points as described above. The results are summarised in figure 4.

Neither the time-course nor the magnitude of Rho activation were significantly affected by either of the two $\beta$-agonists (fig. 4a). Conversely, SNAP slowed the activation of Rho: peak activation occurred at $5 \mathrm{~min}$, compared with $2 \mathrm{~min}$ in the control tissues. Despite this marked slowing of Rho activation, the overall peak magnitude of activation was not significantly different from that seen in the control tissues. Furthermore, deactivation of Rho did not appear to be affected by ISO nor SNAP. At $20 \mathrm{~min}$, Rho activity had decreased by about half and was not significantly different from control.

The changes in Rho activation summarised above were generally mirrored in the changes in ROCK activation (fig. $4 b)$. Overall, neither of the two $\beta$-agonists suppressed the rate or magnitude of ROCK activation compared with control tissues; in fact, at some time-points these activations were greater than in control tissues (fig. $4 \mathrm{~b}$ and c), although the differences did not reach statistical significance. In the SNAPpre-treated tissues, ROCK activation was once again slowed compared to control, with peak activation now occurring at $5 \mathrm{~min}$, followed by nearly complete decay back to baseline by $20 \mathrm{~min}$; however, the absolute magnitude of activation at peak and at 20 min was not significantly different from the control tissues.

Finally, the initial rate of development of tone was unaltered by either of the $\beta$-agonists (fig. $4 \mathrm{c}$ ): tone in these tissues was not significantly different from control tissues at any time-point during the first $5 \mathrm{~min}$, although it was significantly lower than control at $20 \mathrm{~min}$. SNAP pre-treatment appeared to have no effect on development of cholinergic tone: there was no statistically significant difference at any time-point.

\section{Reversal of cholinergically evoked responses}

It has long been recognised that the relaxant effect of $\beta$ adrenoceptor stimulation can vary depending on whether it precedes or follows excitatory stimulation of the smooth 

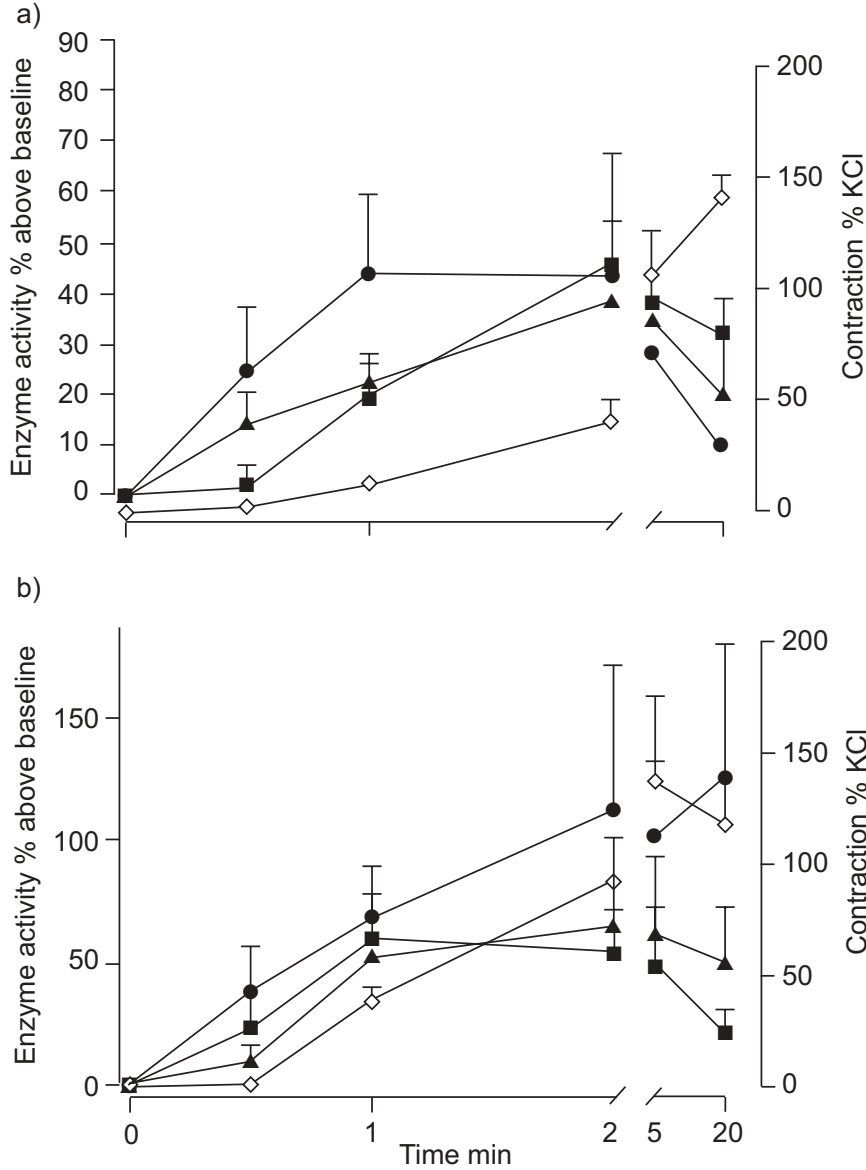

FIGURE 3. Kinetics of carbachol-stimulated RhoA, Rho kinase (ROCK) and mechanical activities. Tissues were challenged with either $2 \times 10^{-7} M(a ; n=4)$ or $10^{-6} \mathrm{M}(\mathrm{b} ; \mathrm{n}=3)$ carbachol, then flash-frozen at times ranging $0-20 \mathrm{~min}$. Symbols indicate mean \pm SEM of RhoA activity evaluated using rhotekin pull-down assay and Western blot $(\bullet)$, ROCK activity measured using either Western blot (phosphorylation of exogenous MYPT; ) or by radiometric assay (incorporation of ${ }^{32} \mathrm{P}$ into MYPT; $\mathbf{\Lambda})$, and tone $(\diamond)$; see Methods for experimental details. Enzymatic effects are expressed as a percentage change above baseline; contractile responses are expressed as a percentage of the response evoked by $60 \mathrm{mM}$ $\mathrm{KCl}$ during the equilibration period.

muscle $[7,26,27]$. The present authors therefore re-examined inhibitory responses in tissues which were first pre-constricted with CCh $\left(2 \times 10^{-7} \mathrm{M}\right)$, then challenged with ISO $\left(10^{-7} \mathrm{M}\right)$ or SNAP $\left(10^{-5} \mathrm{M}\right)$ for $20 \mathrm{~min}$, or with SAL $\left(10^{-7} \mathrm{M}\right)$ for $30 \mathrm{~min}$ (because of its slower onset of action); comparisons were made with control tissues which were challenged with $\mathrm{CCh}$ $\left(2 \times 10^{-7} \mathrm{M}\right)$ alone for $40 \mathrm{~min}$. All tissues were pre-treated for 20 min prior to cholinergic stimulation with the $\mathrm{M}_{2}$-selective cholinergic antagonist AFDX-116 $\left(10^{-6} \mathrm{M}\right)$ in order to obviate functional antagonism of the adrenergic responses via the $\mathrm{M}_{2}$ receptors [33]. All three agonists reversed cholinergically stimulated Rho activation by $\sim 20 \%$, but reversed ROCK activity by $30-40 \%$ (fig. 5); the effects on ROCK activity were statistically significant. All three agonists significantly reversed cholinergically stimulated MLCK activity by $\sim 75 \%$, and nearly abolished cholinergic tone.
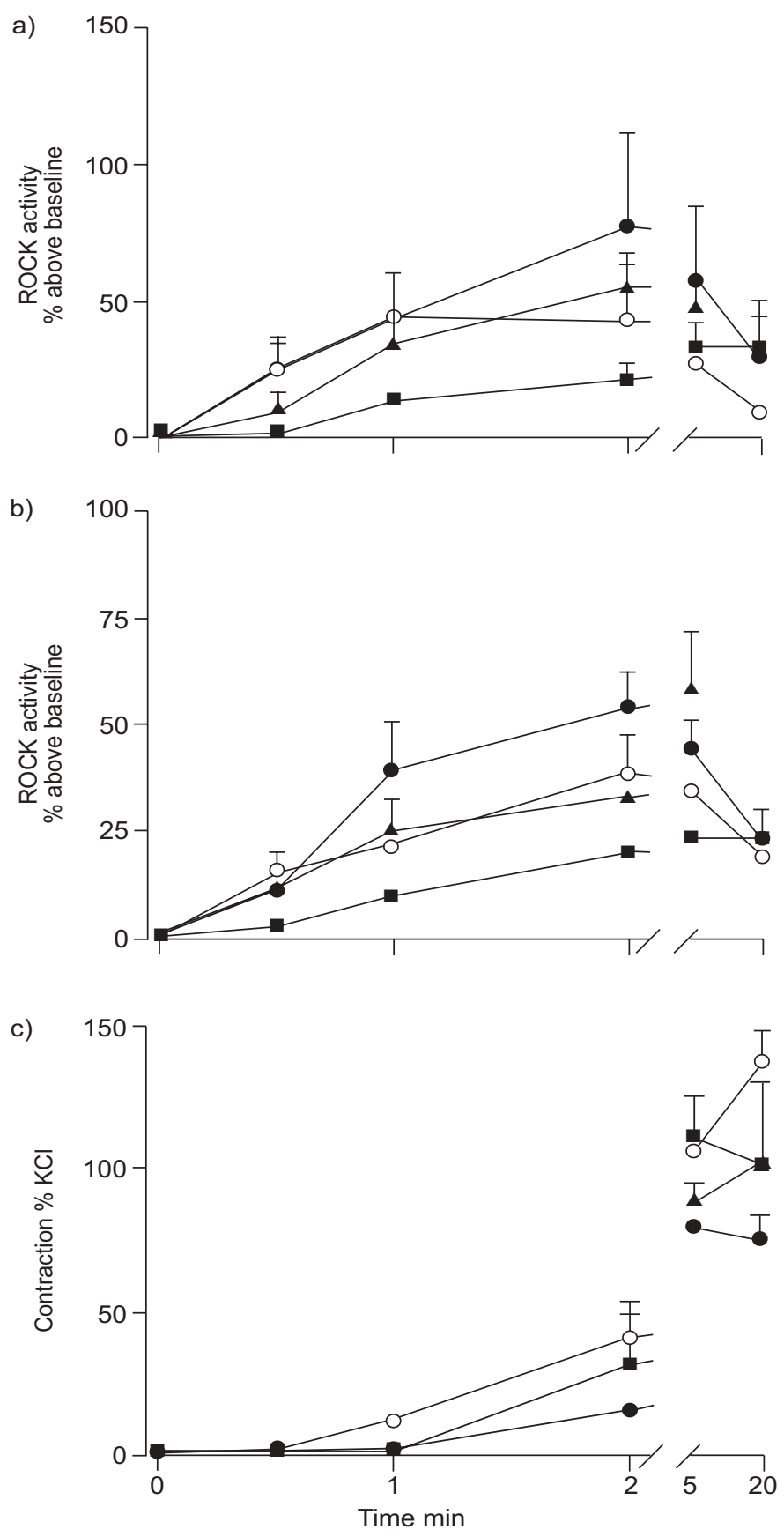

FIGURE 4. Prevention of cholinergic effects on RhoA, Rho kinase (ROCK) and mechanical activities by bronchodilators. Tissues were pretreated with isoproterentol $\left(\bullet ; 10^{-6} \mathrm{M}\right)$ or S-nitroso- $\mathrm{N}$-acetylpenicillamine $\left(\mathbf{\square} ; 10^{-5} \mathrm{M}\right)$ for $30 \mathrm{~min}$, or with salmeterol $\left(\mathbf{\Lambda} ; 10^{-6} \mathrm{M}\right)$ for $60 \mathrm{~min}$, then constricted with $2 \times 10^{-7}$ carbachol, then flash-frozen at times ranging 0-20 min. RhoA (a) and ROCK (b) activities and tone (c) were assayed in the same fashion as summarised in figure 2. Data are expressed as mean \pm SEM. $n=4-6$ for all groups. $\bigcirc$ : vehicle.

\section{DISCUSSION}

While many studies of excitation-contraction coupling in airway smooth muscle have focused on excitatory mechanisms, relatively fewer have scrutinised those underlying bronchodilator responses. Recently, a great deal of attention has been focused upon the RhoA/ROCK signalling pathway 
and its regulation by cholinergic agonists. Most of these have used the sensitivity of contractile responses to ROCK inhibitors, such as Y27632, as indirect indices of Rho/ROCK activities (rather than measuring these activities were not measured directly), and/or only used supramaximally effective concentrations of cholinergic agonist. Few have examined RhoA/ROCK activities per se in ASM, and to the current authors' knowledge, none have done so during submaximal stimulation (which is more physiologically relevant) nor in the presence of bronchodilators (which is more clinically relevant). The current study examined the temporal relationships between RhoA and ROCK activities (measured directly) and tone using two submaximally effective concentrations of CCh with and without simultaneous stimulation with two different $\beta$-agonists and a NO donor. Although ideally this would have been done using tissue from the small airways (given their more important role in determining airflow resistance and in asthma), the considerable amounts of connective tissue, cartilage and epithelium present were found to be problematic (data not shown): these made it difficult to standardise the amount of muscle present prior to homogenisation, especially
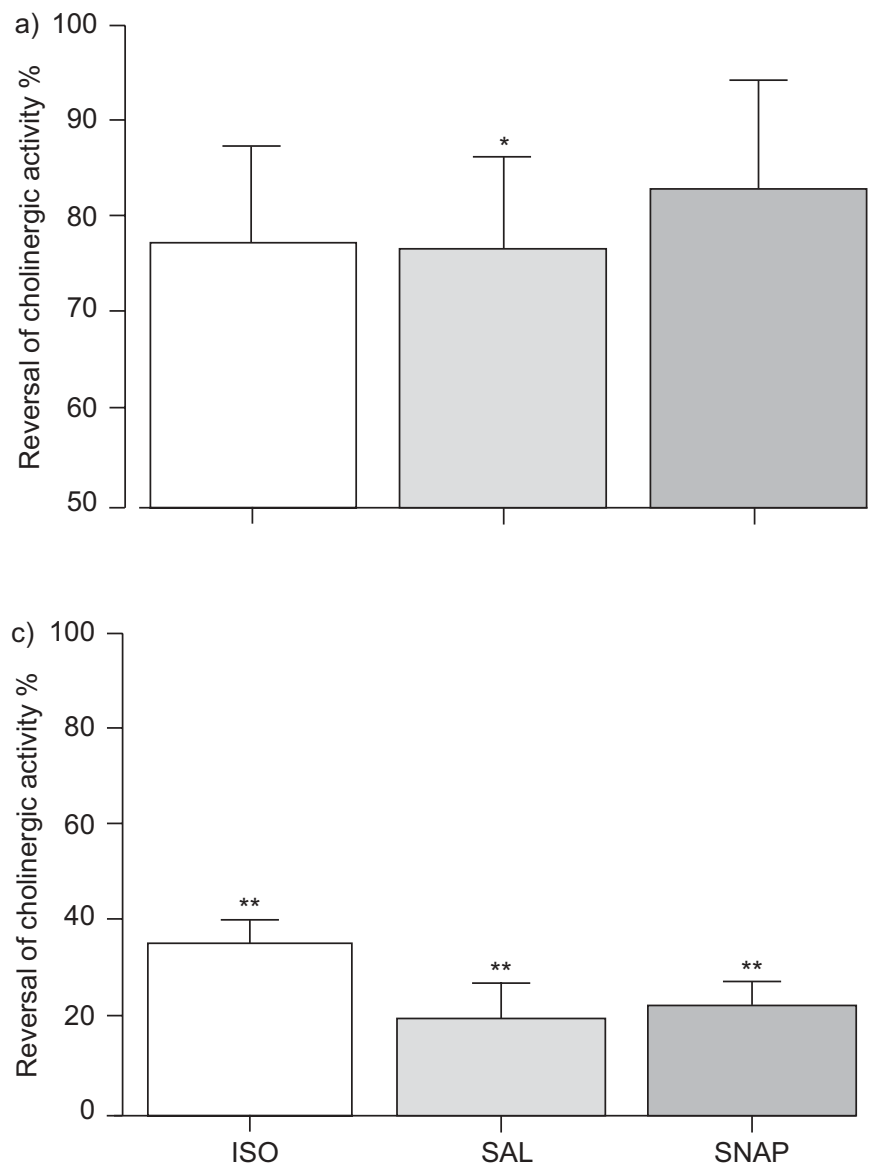

when this involved flash-freezing. The Rho/ROCK activities in nonmuscle cell types (particularly the epithelium) complicated interpretation of the data. For this reason, trachealis smooth muscle, which has been shown to differ in some structural and functional respects from the small airways, was used.

During half-maximally effective cholinergic stimulation, both RhoA and ROCK activities were enhanced markedly above baseline levels. Rho activity increased rapidly (half of the overall response developed within the first $30 \mathrm{~s}$ ), followed shortly thereafter by increased ROCK activity; both activities peaked $2 \mathrm{~min}$ after onset of cholinergic stimulation, then decayed roughly halfway back toward baseline by $20 \mathrm{~min}$. The consequent changes in tone lagged considerably after these: development of tone was negligible at $1 \mathrm{~min}$ (when Rho and ROCK activities were markedly increased), and took $20 \mathrm{~min}$ to reach a peak (at which point Rho and ROCK activities had decayed to roughly $50 \%$ of their peak values). This cholinergic tone is quite stable, being sustained for well over $1 \mathrm{~h}$. (In other studies, this tone has been sustained for several hours; data not shown.)

b)

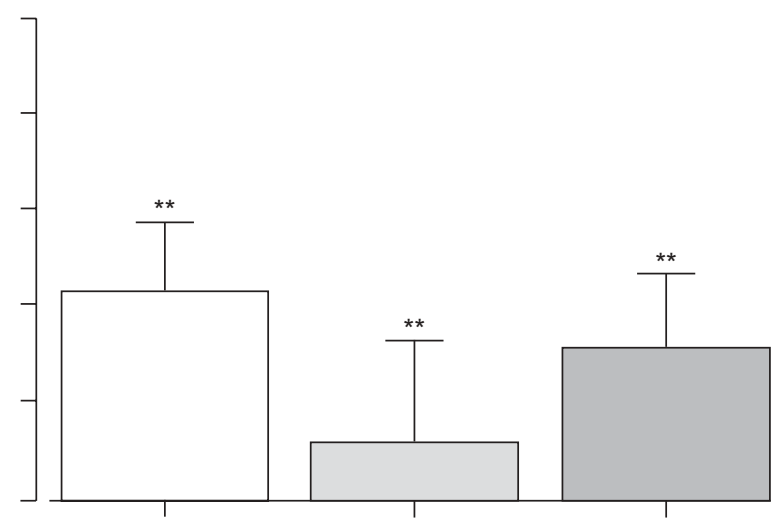

d)

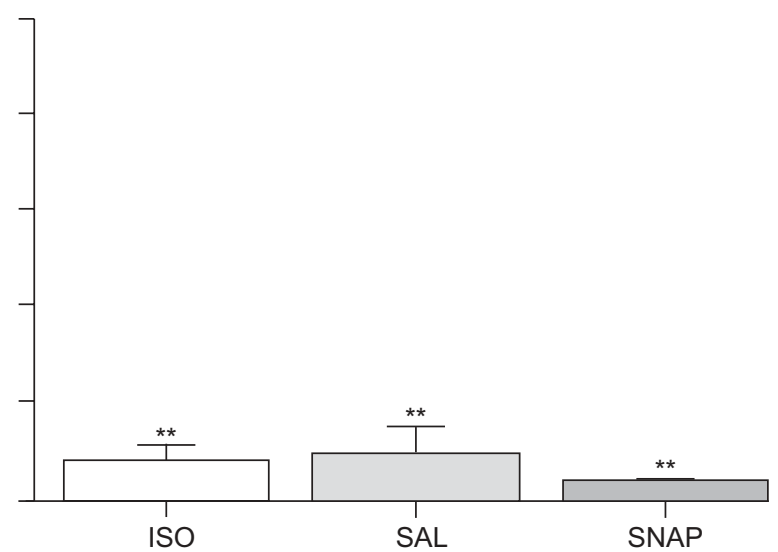

FIGURE 5. Reversal of cholinergically enhanced RhoA, Rho kinase (ROCK), myosin light chain kinase (MLCK) and mechanical activities by bronchodilators Tissues were pre-treated for 20 min with the $\mathrm{M}_{2}$-selective antagonist AFDX-116 (10-6 M), then pre-constricted with carbachol (CCh; $\left.2 \times 10^{-7} \mathrm{M}\right)$ for another 20 min before addition of vehicle, isoproterentol (ISO; $10^{-7} \mathrm{M}$ ) or S-nitroso- $\mathrm{N}$-acetylpenicillamine (SNAP; $10^{-5} \mathrm{M}$ ) for $20 \mathrm{~min}$, or with salmeterol (SAL; $10^{-7} \mathrm{M}$ ) for 30 min. Tissues were then flash-frozen and assayed for Rho, ROCK or MLCK activities: these were expressed as a percentage of the activities measured in matched tissues challenged with CCh alone for 40 min. Tone existing immediately prior to flash-freezing was standardised as a percentage of that existing immediately prior to addition of the bronchodilators. Bars indicate the mean changes in enzyme activities or tone induced by ISO, SNAP or SAL. $n>5$ for all. ANOVA was used to determine whether the decrease from control levels were statistically significant. ${ }^{*}: p<0.05 ;{ }^{* *}: p<0.01$. 
These cholinergic effects were dose dependent in that increasing the concentration of CCh five-fold (still less than maximally effective with respect to contractions) enhanced RhoA and ROCK activities nearly twice as much as did $2 \times 10^{-7} \mathrm{M}$ CCh. Moreover, the kinetics were accelerated, with peak activation now occurring by $1 \mathrm{~min}$ after cholinergic stimulation. Interestingly, Rho and ROCK activities then began to decrease toward baseline levels over the next 15-20 min, despite maintained stimulation with the nonhydrolysable cholinergic agonist, and despite continued development of tone; this finding diverges from what has been shown in vascular and intestinal smooth muscles [34, 35], wherein Rho/ ROCK stimulation is sustained (i.e., does not exhibit a decrease toward baseline). Other excitation-contraction coupling mechanisms, such as $\mathrm{Ca}^{2+}$ release [29], may become more important during these later periods of prolonged contraction. It could be argued that these measures of Rho/ROCK activities were underestimates, since the data were obtained in the presence of the nonsteroidal anti-inflammatory drug indomethacin (used here to inhibit endogenous prostanoid synthesis), which others have shown may inhibit Rho/ROCK signalling in some cell types [36, 37]. However, that novel effect of indomethacin requires concentrations of indomethacin considerably higher than those employed in the current study $(100 \mu \mathrm{M}$ [36] versus $10 \mu \mathrm{M})$. That notwithstanding, the changes in Rho/ROCK activities presented here using submaximal excitatory stimulation were of the same order as those shown previously in other cell types maximally stimulated by other means [24, 38].

Regarding the second objective of the current study (to investigate the regulation of Rho and ROCK by bronchodilators), cholinergic stimulation of Rho and ROCK activities was found to be largely insensitive to pre-treatment with either of the two $\beta$-adrenoceptor agonists: neither the magnitude nor the kinetics of RhoA/ROCK signalling were suppressed, although tone was markedly decreased. In fact, there was a suggestion that pre-treatment with the $\beta$-agonists might slightly increase cholinergically induced ROCK activity (fig. $4 \mathrm{~b}$ ), and this could account in part for the finding that longterm or excessive use of $\beta$-agonists may actually worsen asthma [39]. In contrast to their inability to prevent or slow the increase in Rho and ROCK activities induced by subsequent cholinergic challenge, both $\beta$-agonists did markedly reverse the levels of activity of these enzymes during the peak of cholinergic stimulation. In addition to their effect on RhoA/ ROCK signalling, the $\beta$-agonists and SNAP markedly suppressed MLCK activity (fig. 5), an effect that has been described in more detail previously [7] and is beyond the scope of the current study. Others have previously documented this paradox, whereby the interactions between $\beta$-adrenergic and cholinergic stimulation in airway smooth muscle depend on the order in which these functionally opposing stimuli are delivered, and have attributed it to interactions between PKA, MLCK and/or other $\mathrm{Ca}^{2+} /$ calmodulin-dependent enzymes [7, 26, 27]. As such, the prophylactic use of bronchodilators may be less justified than their use as a rescue medication [39].

Conversely, the NO donor SNAP markedly slowed the activation of Rho and ROCK upon cholinergic stimulation (although the peak and sustained levels of Rho stimulation were not significantly different from the control tissues), in addition to its ability to suppress their activities following cholinergic stimulation. The effects of NO on RhoA translocation per se remain to be investigated.

The signalling events that couple activation of $\beta$-adrenoceptors or guanylate cyclase with changes in Rho/ROCK activities are as yet unclear. The current authors have previously shown that Rho/ROCK activities are in part $\mathrm{Ca}^{2+}$ dependent $[28,40]$, and $\beta$-agonists and $\mathrm{NO}$ are known to decrease intracellular calcium levels in airway smooth muscle; however, the present study did not control for changes in intracellular calcium. Future studies of the mechanisms by which $\beta$-adrenoceptors couple to the Rho/ROCK signalling pathway will require a careful pharmacological dissection using agents that abrogate one or another of the excitation-contraction coupling pathways. In addition to cyclic adenosine monophosphate and/or PKA, it is also possible that cyclic guanosine monophosphate (cGMP) and/or PKG are involved, given the well-documented phenomenon of cross-talk between these two signalling pathways. Several recent studies using vascular smooth muscle have documented an inhibition of Rho/ROCK via a cGMPdependent pathway $[25,35]$. As such, it will be necessary to use selective blockers of the two pathways to resolve this question. Another candidate for this coupling is telokin, a substrate of PKA and PKG, which has been shown to stimulate MLCP directly in vascular smooth muscle $[10,41]$, but which may also act by suppressing Rho/ROCK; there have been no investigations of this protein in the regulation of ROCK in ASM.

In conclusion, the current authors have described for the first time the temporal relationships in airway smooth muscle between cholinergic stimulation of RhoA and Rho kinase activities and tone, and shown these to be inhibited by $\beta$ agonists and a nitric oxide donor, although the major effect of the bronchodilators appears to be on myosin light chain kinase activity.

\section{REFERENCES}

1 Jones CA, Madison JM, Tom-Moy M, Brown JK. Muscarinic cholinergic inhibition of adenylate cyclase in airway smooth muscle. Am J Physiol 1987; 253: C97-C104.

2 Madison JM, Yamaguchi H. Muscarinic inhibition of adenylyl cyclase regulates intracellular calcium in single airway smooth muscle cells. Am J Physiol 1996; 270: L208-L214.

3 Roux E, Molimard M, Savineau JP, Marthan R. Muscarinic stimulation of airway smooth muscle cells. Gen Pharmacol 1998; 31: 349-356.

4 Chilvers ER, Batty IH, Barnes PJ, Nahorski SR. Formation of inositol polyphosphates in airway smooth muscle after muscarinic receptor stimulation. J Pharmacol Exp Ther 1990; 252: 786-791.

5 Kajita J, Yamaguchi H. Calcium mobilization by muscarinic cholinergic stimulation in bovine single airway smooth muscle. Am J Physiol 1993; 264: L496-L503.

6 Gerthoffer WT. Calcium dependence of myosin phosphorylation and airway smooth muscle contraction and relaxation. Am J Physiol 1986; 250: C597-C604. 
7 Kotlikoff MI, Kamm KE. Molecular mechanisms of betaadrenergic relaxation of airway smooth muscle. Annu Rev Physiol 1996; 58: 115-141.

8 Janssen LJ, Sims SM. Acetylcholine activates non-selective cation and chloride conductances in canine and guinea-pig tracheal myocytes. J Physiol 1992; 453: 197-218.

9 Janssen LJ, Sims SM. Emptying and refilling of $\mathrm{Ca}^{2+}$ store in tracheal myocytes as indicated by ACh-evoked currents and contraction. Am J Physiol 1993; 265: C877-C886.

10 Somlyo AP, Somlyo AV. $\mathrm{Ca}^{2+}$ sensitivity of smooth muscle and nonmuscle myosin II: modulated by $G$ proteins kinases and myosin phosphatase. Physiol Rev 2003; 83: 1325-1358.

11 lizuka K, Yoshii A, Samizo K, et al. A major role for the Rho-associated coiled coil forming protein kinase in Gprotein-mediated $\mathrm{Ca}^{2+}$ sensitization through inhibition of myosin phosphatase in rabbit trachea. Br J Pharmacol 1999; 128: 925-933.

12 Janssen LJ, Tazzeo T, Zuo J, Pertens E, Keshavjee S. $\mathrm{KCl}$ evokes contraction of airway smooth muscle via activation of RhoA and Rho-kinase. Am J Physiol Lung Cell Mol Physiol 2004; 287: L852-L858.

13 Janssen LJ, Wattie J, Lu-Chao H, Tazzeo T. Muscarinic excitation-contraction coupling mechanisms in tracheal and bronchial smooth muscles. J Appl Physiol 2001; 91: 1142-1151.

14 Setoguchi H, Nishimura J, Hirano K, Takahashi S, Kanaide $\mathrm{H}$. Leukotriene $\mathrm{C}_{4}$ enhances the contraction of porcine tracheal smooth muscle through the activation of Y-27632, a rho kinase inhibitor sensitive pathway. $\mathrm{Br} J$ Pharmacol 2001; 132: 111-118.

15 Smith PG, Roy C, Zhang YN, Chauduri S. Mechanical stress increases RhoA activation in airway smooth muscle cells. Am J Respir Cell Mol Biol 2003; 28: 436-442.

16 Togashi H, Emala CW, Hall IP, Hirshman CA. Carbacholinduced actin reorganization involves $\mathrm{G}_{\mathrm{i}}$ activation of Rho in human airway smooth muscle cells. Am J Physiol 1998; 274: L803-L809.

17 Yoshii A, Iizuka K, Dobashi K, et al. Relaxation of contracted rabbit tracheal and human bronchial smooth muscle by Y-27632 through inhibition of $\mathrm{Ca}^{2+}$ sensitization. Am J Respir Cell Mol Biol 1999; 20: 1190-1200.

18 Chiba Y, Sakai H, Misawa M. Augmented acetylcholineinduced translocation of RhoA in bronchial smooth muscle from antigen-induced airway hyperresponsive rats. $\mathrm{Br} J$ Pharmacol 2001; 133: 886-890.

19 Chiba Y, Sakai H, Wachi H, Sugitani H, Seyama Y, Misawa M. Upregulation of rhoA mRNA in bronchial smooth muscle of antigen-induced airway hyperresponsive rats. J Smooth Muscle Res 2003; 39: 221-228.

20 Chiba Y, Misawa $\mathrm{M}$. The role of RhoA-mediated $\mathrm{Ca}^{2+}$ sensitization of bronchial smooth muscle contraction in airway hyperresponsiveness. J Smooth Muscle Res 2004; 40: 155-167.

21 Hashimoto K, Peebles RS Jr, Sheller JR, et al. Suppression of airway hyperresponsiveness induced by ovalbumin sensitisation and RSV infection with Y-27632 a Rho kinase inhibitor. Thorax 2002; 57: 524-527.

22 Hunter I, Cobban HJ, Vandenabeele P, MacEwan DJ, Nixon GF. Tumor necrosis factor-alpha-induced activation of RhoA in airway smooth muscle cells: role in the $\mathrm{Ca} 2+$ sensitization of myosin light chain 20 phosphorylation. Mol Pharmacol 2003; 63: 714-721.

23 Bolz SS, Vogel L, Sollinger D, et al. Nitric oxide-induced decrease in calcium sensitivity of resistance arteries is attributable to activation of the myosin light chain phosphatase and antagonized by the RhoA/Rho kinase pathway. Circulation 2003; 107: 3081-3087.

24 Murthy KS, Zhou H, Grider JR, Brautigan DL, Eto M, Makhlouf GM. Differential signalling by muscarinic receptors in smooth muscle: $\mathrm{m} 2$-mediated inactivation of myosin light chain kinase via $\mathrm{G}_{\mathrm{i} 3} \mathrm{Cdc} 42 / \mathrm{Rac1}$ and $\mathrm{p} 21-$ activated kinase 1 pathway and m3-mediated $\mathrm{MLC}_{20}$ (20 kDa regulatory light chain of myosin II) phosphorylation via Rho-associated kinase/myosin phosphatase targeting subunit 1 and protein kinase C/CPI-17 pathway. Biochem J 2003; 374: 145-155.

25 Sauzeau V, Le Jeune H, Cario-Toumaniantz C, et al. Cyclic GMP-dependent protein kinase signaling pathway inhibits RhoA-induced $\mathrm{Ca}^{2+}$ sensitization of contraction in vascular smooth muscle. J Biol Chem 2000; 275: 21722-21729.

26 Tansey MG, Luby-Phelps K, Kamm KE, Stull JT. $\mathrm{Ca}^{2+}$ dependent phosphorylation of myosin light chain kinase decreases the $\mathrm{Ca}^{2+}$ sensitivity of light chain phosphorylation within smooth muscle cells. J Biol Chem 1994; 269: 9912-9920.

27 Word RA, Tang DC, Kamm KE. Activation properties of myosin light chain kinase during contraction/relaxation cycles of tonic and phasic smooth muscles. J Biol Chem 1994; 269: 21596-21602.

28 Janssen LJ, Tazzeo T, Zuo J. Enhanced myosin phosphatase and $\mathrm{Ca}^{2+}$-uptake mediate adrenergic relaxation of airway smooth muscle. Am J Respir Cell Mol Biol 2004; 30: 548-554.

29 Bai Y, Sanderson MJ. Modulation of the $\mathrm{Ca}^{2+}$ sensitivity of airway smooth muscle cells in murine lung slices. Am J Physiol Lung Cell Mol Physiol 2006; 291: L208-L221.

30 Hartshorne DJ, Ito M, Erdodi F. Myosin light chain phosphatase: subunit composition interactions and regulation. J Muscle Res Cell Motil 1998; 19: 325-341.

31 Ikebe M, Hartshorne DJ. Effects of $\mathrm{Ca}^{2+}$ on the conformation and enzymatic activity of smooth muscle myosin. J Biol Chem 1985; 260: 13146-13153.

32 Kirkpatrick CT, Rooney PJ. Contractures produced by carbamate anticholinesterases in bovine tracheal smooth muscle. Clin Exp Pharmacol Physiol 1982; 9: 603-611.

33 Janssen LJ, Daniel EE. Pre- and postjunctional muscarinic receptors in canine bronchi. Am J Physiol 1990; 259: L304-L314.

34 Sakurada S, Okamoto H, Takuwa N, Sugimoto N, Takuwa Y. Rho activation in excitatory agonist-stimulated vascular smooth muscle. Am J Physiol Cell Physiol 2001; 281: C571-C578.

35 Murthy KS, Zhou H, Grider JR, Makhlouf GM. Inhibition of sustained smooth muscle contraction by PKA and PKG preferentially mediated by phosphorylation of RhoA. Am J Physiol Gastrointest Liver Physiol 2003; 284: G1006-G1016.

36 Weggen S, Eriksen JL, Das P, et al. A subset of NSAIDs lower amyloidogenic A $\beta 42$ independently of cyclooxygenase activity. Nature 2001; 414: 212-216. 
37 Zhou Y, Su Y, Li B, et al. Nonsteroidal anti-inflammatory drugs can lower amyloidogenic $\mathrm{A} \beta_{42}$ by inhibiting Rho. Science 2003; 302: 1215-1217.

38 Yoneda A, Multhaupt HA, Couchman JR. The Rho kinases I and II regulate different aspects of myosin II activity. J Cell Biol 2005; 170: 443-453.

39 Sears MR. The evolution of $\beta 2$-agonists. Respir Med 2001; 95: Suppl. B, S2-S6.
40 Liu C, Zuo J, Pertens E, Helli PB, Janssen LJ. Regulation of Rho/ROCK signaling in airway smooth muscle by membrane potential and $\left[\mathrm{Ca}^{2+}\right]_{\mathrm{i}}$. Am J Physiol Lung Cell Mol Physiol 2005; 289: L574-L582.

41 Choudhury N, Khromov AS, Somlyo AP, Somlyo AV. Telokin mediates $\mathrm{Ca}^{2+}$-desensitization through activation of myosin phosphatase in phasic and tonic smooth muscle. J Muscle Res Cell Motil 2004; 25: 657-665. 